\title{
Durability of structural lightweight waste aggregate concrete - electrical resistivity
}

\author{
Marie Hornakova ${ }^{1, *}$, Petr Konecny ${ }^{1}$, Petr Lehner $^{1}$ and Jacek Katzer ${ }^{2}$ \\ ${ }^{1}$ VSB - Technical University of Ostrava, Faculty of Civil Engineering, Department of Structural \\ Mechanics, Ludvíka Podéště 1875/17, 70833 Ostrava-Poruba, Czech Republic \\ ${ }^{2}$ University of Warmia and Mazury, Olsztyn, Poland
}

\begin{abstract}
While examination of the durability of ordinary concrete mixtures is of interest of many research groups, only limited amount of information is available in terms of lightweight concrete tested under the same conditions. In this case, the durability related to the chloride ion diffusion is investigated on the relatively new type of structural lightweight concrete, which, above all, contains waste material - red ceramics sand, and artificial expanded clay coarse aggregate. Used aggregates were fully soaked before adding into the concrete mixture, so also the internal curing effect is considered in terms of the degradation process. Cylindrical specimens made of plain concrete matrix and with added fibre in various percentage quantities were tested to examine the durability of the mixture by measuring the electrical resistivity. The results are compared to the findings from a similar project. The paper deals with aspects influencing the results of chloride diffusion in concrete.
\end{abstract}

\section{Introduction}

There is a growing interest in the field of sustainability, preservation of the environment and protection of the rapidly decreasing reserves of natural resources. Whereas there is a critical shortage of natural aggregates for production of new concrete, there is also a massive amount of demolished concrete or newly manufactured unsuitable (lower quality) building material, which cause severe ecological problems [1]. The solution could be reusing of the waste material as aggregate to the new concrete [2, 3, 4].

The aim of the article is to examine the durability in case of chloride diffusion of the structural lightweight concrete (SLWAC) made of waste red ceramic fine aggregate and artificial clay coarse aggregate, which has been designed and mechanical properties have been tested in previous research [5]. Copper coated steel fibres were used as a reinforcement. Aggregates were pre-soaked and no additional water has been added to the mixture during the mixing process. Therefore, during the harnessing, concrete benefitted from the process of internal curing, which is a phenomenon based on slowly releasing the water from the aggregate for hydration of the cement. This process can reduce the autonomous shrinkage, which could be useful in case of avoidance of microcracks on the surface of concrete, that usually leads to higher ingress rate into concrete [6].

* Corresponding author: marie.hornakova@vsb.cz 
The fibre reinforcement is added to concrete also as a protection against microcracks and for improvement of the material characteristics, but in a long-term and durability perspective, it is still a subject of interest.

Used porous material served well for the process of internal curing, but it is needed to examine its behaviour over the ageing of concrete. For this purpose, cylindrical specimens of every type of concrete mixture $\left(V_{f}=0.0 \%\right.$ - plain concrete, $0.5 \%, 1.0 \%$, $1.5 \%$ ) have been tested. Resistivity has been measured on the specimens continuously in specific time intervals from the casting. The obtained results are compared to the results of different types of mixture from a similar project [7].

Important part of this project is to develop knowledge about the usage of waste red ceramic aggregate, also from a durability point of view. Red ceramic sand was used in this project because of a specific reason - in the European Union, it is forbidden to build from ceramic elements, which have not passed the quality control test. In accordance with this regulation, the unsuitable elements are usually destroyed, which creates a problem of recycling or utilization of piling up ceramic debris.

\section{Methodology}

\subsection{Chloride ingress}

Chloride ions can migrate through the concrete as a result of a concentration gradient (diffusion), a pressure gradient causing the flow of chloride bearing solutions through pores, and capillary action. Among these transport options, the diffusion is the most damaging process in case of the initiation of corrosion of the steel reinforcement of highway structures in mild climate and marine environment. If the cracks are absent, chloride diffusion is dependent mostly on the nature of the porosity. Low rate of diffusion is achieved when the total volume fraction of porosity and constrictivity is low and its tortuosity is high [8].

The rate of chloride ingress into concrete is affected also by the concrete's binding capacity. Concrete is not an inert material in terms of chloride ions in the pore solution. A part of the ions reacts with the concrete matrix and becomes physically or chemically bounded which reduces the rate of diffusion. Only the free chloride will diffuse through the structure. If the steady-state conditions have not been reached before testing, the results may be affected. Binding capacity of the specific concrete mixture is related to the used cementitious materials. Also, the inclusion of supplementary cementitious materials may affect the binding phenomenon. Hence, the exact influence is of interest of many research teams [e.g. 9, 10]. In this case, there has been an attempt to use the waste red ceramic fine aggregate as a partial cementitious substitution.

However, there is a lot of other parameters that influence the chloride ingress (surface chloride content, the temperature at the time of casting, the age of the structure etc.) [8].

\subsubsection{Numerical modelling of chloride ingress}

The chloride penetration through the concrete can be generally modelled as a function of depth and time using Fick's Second Law of Diffusion [11] - eq. 1, because, as mentioned above, the diffusion is the predominant transport mechanism of chloride into concrete $[8,12]$. This applies without distinction whether the process is in steady-state or not.

$$
\frac{\partial C(x, t)}{\partial t}=D_{c} \frac{\partial^{2} C(x, t)}{\partial x^{2}}
$$


where $C(x, t)$ (\% weight of cement) is the chloride ion concentration at a distance $x(\mathrm{~m})$ from the surface of the concrete in time $t(\mathrm{~s}) ; D_{c}\left(\mathrm{~m}^{2} / \mathrm{s}\right)$ is effective diffusion coefficient, which characterizes the ability of concrete to withstand the penetration of chlorides [13].

\subsubsection{Electrical resistivity and ion diffusivity}

There are different ways how to test the chloride permeability; long-term tests, such are bulk diffusion test or salt ponding test; and short-term tests, for instance, the rapid chloride permeability test or pressure penetration test. Resistivity techniques can be also used as methods of assessing the ability of chlorides to penetrate the concrete and the main advantage is that the testing procedure is very easy and fast.

Concrete resistivity is an important parameter in durability modelling. It is a property of the material that describes the ability to transport electrical charge of the chloride ions. Corrosion current density decreases as the electrical resistivity increases, which means that the corrosion rate reduces [12].

The relationship between the electrical resistivity and ion diffusivity can be expressed by the Nernst-Einstein equation (eq. 2) [14]. This theoretical approach is used to obtain the diffusion coefficient.

$$
D=\frac{R T}{Z^{2} F^{2}} x \frac{t_{i}}{\gamma_{1} C_{i} \rho_{B R}},
$$

where $D$ is diffusivity of the chloride ion $\left[\mathrm{m}^{2} / \mathrm{s}\right] ; R$ is universal gas constant $[\mathrm{J} / \mathrm{Kmol}] ; T$ is absolute temperature $[\mathrm{K}] ; Z$ is ionic valence $[-] ; F$ is Faraday constant $[\mathrm{C} / \mathrm{mol}] ; t_{i}$ is transfer number of chloride ion [-]; $\gamma_{i}$ is activity coefficient for chloride ion [-]; $C_{i}[\mathrm{C} / \mathrm{mol}]$ is concentration of ions $i$ in the pore water and $\rho_{B R}$ is bulk electrical resistivity $[\Omega \mathrm{m}]$. The diffusivity of chloride ions in concrete can be calculated by the Nernst-Einstein equation only if the transfer number is equal to one $[14,15,16]$.

The Wenner Array Probe method can be used for determination of the concrete resistivity. It consists of four points in a constant distance $a$ (approximately $5 \mathrm{~cm}$ ) - Fig. 1 , that are applied on the surface of the specimen. The two outer points are where the current is applied, and the inner two points measure the potential, which reduces the effect of polarization as the actual potential is measured across an inner region. The method is non-destructive, so the test can be repeated to determine the diffusion process dependent on time.

Despite the simplicity of the method, there is a risk of the relatively large variation of results because of the heterogeneity of the material and the possibility of uneven contact condition. The electrodes are applied to the concrete surface with the help of wet sponges, so the connection may be influenced by contact pressure level and the saturation of the sponge [7].

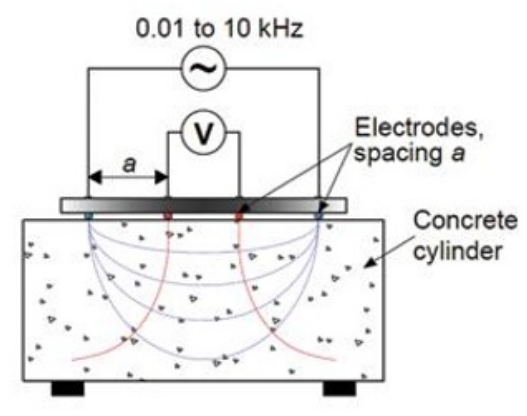

Fig. 1. Wenner Array probe [17]. 
The device measures the surface resistance of the concrete; the relationship between bulk and surface resistivity of the material is given by eq. 3 [18].

$$
\rho_{B R}=\frac{\rho_{S R}}{K},
$$

where $\rho_{S R}$ is the surface (or apparent) resistance of the concrete $[\Omega \mathrm{m}]$ measured by the device and $K[-]$ is a geometric factor dependent on the size and shape of the specimen and the distance between the probes on the testing device.

\subsection{Used materials and designed concrete mixture}

Concrete mixture contains cement I $42.5 \mathrm{~N}-\mathrm{NA}$, pre-soaked red ceramic sand (Fig. 2a), presoaked artificial expanded clay aggregate (Fig. 2b) and copper coated steel fibres (Fig. 2c) in various volumes of concrete. The proportions of the mixture are given in Table 1.

Requirements have been established that have affected the design of the mixture: no additional water, the amount of cement circa $300 \mathrm{~kg} / \mathrm{m} 3$, good workability of the fresh mix and minimum voids on the surface of samples (closed structure) - Fig. 3a. The internal structure of the concrete is shown in Fig. $3 b$.

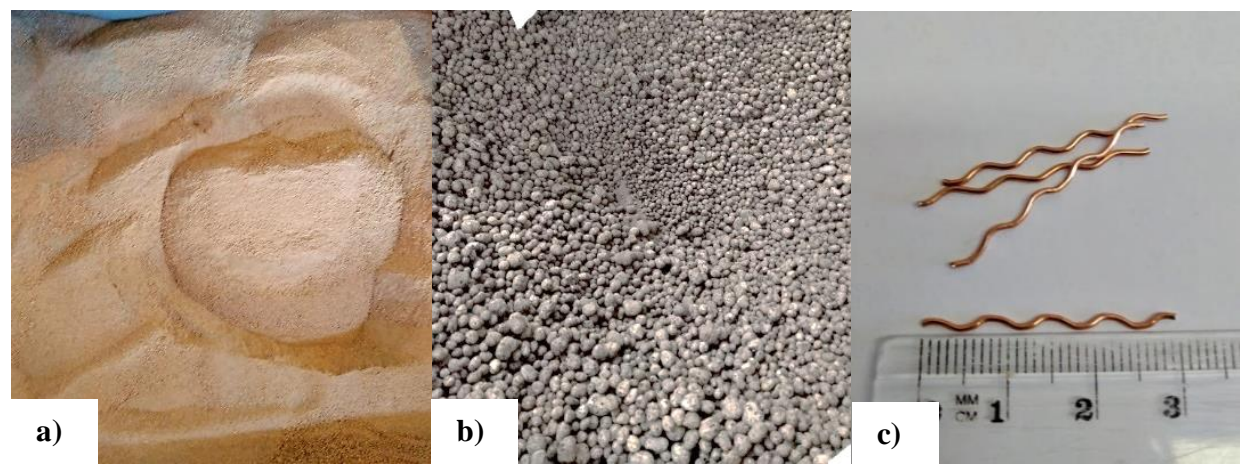

Fig. 2. Used materials a) waste red ceramic fine aggregate, b) expanded clay coarse aggregate, c) copper coated steel fibre.

Table 1. Mixture proportions for a cubic meter of SLWAC.

\begin{tabular}{|c|c|c|c|}
\hline & $\begin{array}{c}\text { SLWAC } \\
{\left[\mathrm{kg} / \mathrm{m}^{3}\right]}\end{array}$ & \multicolumn{2}{|c|}{$\begin{array}{c}\text { Fibre } \\
{\left[\mathrm{kg} / \mathrm{m}^{3}\right]}\end{array}$} \\
\hline Waste red ceramic aggregate - pre-soaked & 700.71 & $S L W A C$ & 0.0 \\
\hline Expanded clay aggregate - pre-soaked & 386.05 & $S L W A C+0.5 \%$ & 39.0 \\
\hline Cement I 42.5 N-NA & 320.49 & $S L W A C+1.0 \%$ & 78.0 \\
\hline Water in the pores & 461.31 & $S L W A C+1.5 \%$ & 117.0 \\
\hline
\end{tabular}




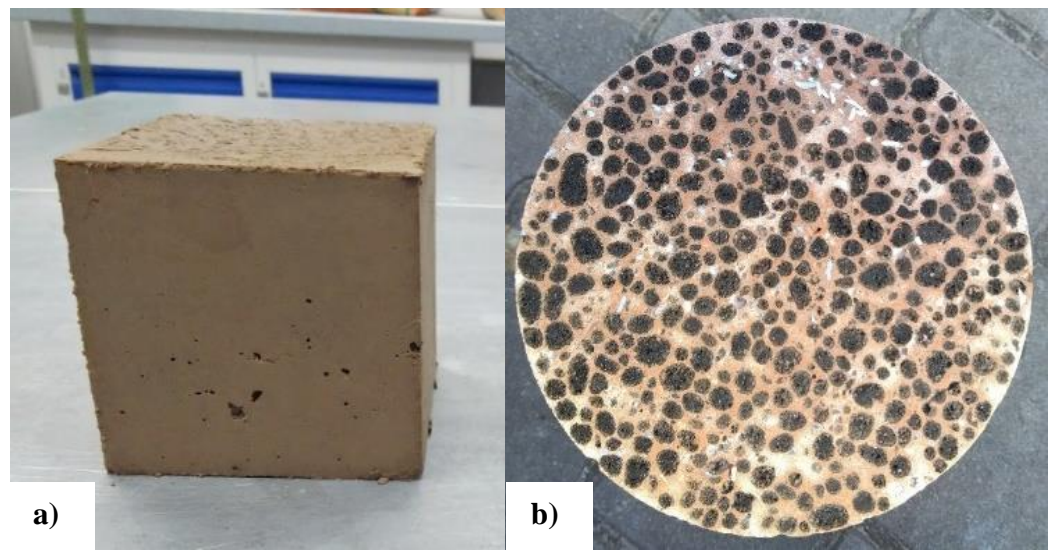

Fig. 3. a) Closed structure of the surface. b) Detail of the internal structure of the concrete.

\subsection{Preparation of the specimens}

The specimens were prepared at the laboratories of Koszalin University of Technology, where have been also tested the mechanical properties of the mixture, and at VŠB Technical University of Ostrava, the specimens have been tested in terms of resistivity.

Concrete mixtures have been tested immediately after casting for slump and after 28 days from casting for compressive strength, splitting tensile strength, static and dynamic modulus of elasticity, flexural characteristics and shear strength. The results are described in detail in [5].

Three cylindrical specimens of every type of concrete mixture (SLWAC - plain concrete; SLWAC+0.5\%, SLWAC+1.0\% and SLWAC+1.5\% - mixtures with the specific amount of fibre - Table 1) with a diameter approximately $100 \mathrm{~mm}$ and height $220 \mathrm{~mm}$, were used for measuring of the concrete resistance. For the first 24 hours after casting, the specimens were kept in their moulds tightly covered with polyethylene sheets. Then, the specimens were removed from the moulds and cured in a water tank.

The resistance has been measured in specific time points (7, 14, 28, 46 and 91 days) after the casting on a total of 12 saturated specimens with dry surface four times around a diameter. The last values, usually measured 161 days after casting, have not been measured yet.

\subsection{Reference project}

Similar project previously prepared by co-authors [7] is used for comparison of the results. The characteristics of the mixtures used in the task are given in Table 2. As a reference concrete was used concrete made of ordinary Portland cement (OPC) and the investigated mixtures were made of self-compacting concrete (SCC) with steel fibre reinforcement KE20/1.7 in amount $0 \%, 1 \%$ and $2 \%$ of weight.

A complete set of tests have been performed in the project, including measurements of the basic mechanical properties, fracture tests, electrical resistance test according to AASHTO-TP95 [19], the chloride rapid penetration test according to ASTM C1202 [20] and accelerated chloride penetration test according to Nordtest NTBuild 443 [21]. 
Table 2. Mixture proportions for a cubic meter of OPC and SCC [7].

\begin{tabular}{|c|c|c|c|c|}
\hline Mixture No. & OPC & SCC+0\% & SCC+1\% & SCC+2\% \\
\hline Cement type I 42.5 R & $313 \mathrm{~kg} / \mathrm{m}^{3}$ & \multicolumn{3}{|c|}{$490 \mathrm{~kg} / \mathrm{m}^{3}$} \\
\hline Water & $164 \mathrm{~kg} / \mathrm{m}^{3}$ & \multicolumn{3}{|c|}{$201 \mathrm{~kg} / \mathrm{m}^{3}$} \\
\hline Sand & $387 \mathrm{~kg} / \mathrm{m}^{3}$ & \multicolumn{3}{|c|}{$807 \mathrm{~kg} / \mathrm{m}^{3}$} \\
\hline River gravel & $1546 \mathrm{~kg} / \mathrm{m}^{3}$ & \multicolumn{3}{|c|}{$807 \mathrm{~kg} / \mathrm{m}^{3}$} \\
\hline Superplasticizer & - & \multicolumn{3}{|c|}{$12.25 \mathrm{~kg} / \mathrm{m}^{3}$} \\
\hline Stabilizer & - & \multicolumn{3}{|c|}{$1.96 \mathrm{~kg} / \mathrm{m}^{3}$} \\
\hline Steel Fibres & - & - & $80 \mathrm{~kg} / \mathrm{m}^{3}$ & $160 \mathrm{~kg} / \mathrm{m}^{3}$ \\
\hline Water/cement ratio (W/C) & 0.52 & \multicolumn{3}{|c}{0.41} \\
\hline
\end{tabular}

\section{Results and discussion}

Surface resistivity measured by the Wenner Array Probe is given in Table 3, the classification of concrete can be determined according to AASHTO TP 95 [19]. In this case, the measured surface resistivity shows that the chloride ion permeability is high $\left(\rho_{S R}<12 \mathrm{k} \Omega \mathrm{cm}\right)$ on every specimen in every time point. The classification of bulk resistivity by ASTM C1202 [20] shows the same results (high chloride ion permeability if $\rho_{B R}<4.5 \mathrm{k} \Omega \mathrm{cm}$ ). Results of the diffusion coefficient are given also in Table 3.

Based on the results, one should note that the concrete mixtures become more resistant over the time and less resistant with the amount of added fibre.

Table 3. Results of resistivity and diffusion coefficient over the time for all tested mixtures.

\begin{tabular}{|c|c|c|c|c|c|}
\hline Time [days] & 7 & 14 & 28 & 56 & 91 \\
\hline \multicolumn{6}{|c|}{ Surface resistivity $\rho_{\mathrm{SR}}[\mathrm{k} \Omega \mathrm{cm}]$} \\
\hline SLWAC & 7.29 & 8.34 & 8.52 & 8.65 & 10.50 \\
\hline SLWAC $+0.5 \%$ & 6.24 & 6.76 & 7.53 & 8.22 & 9.10 \\
\hline SLWAC $+1.0 \%$ & 4.84 & 5.68 & 6.58 & 7.12 & 8.31 \\
\hline SLWAC $+1.5 \%$ & 3.96 & 4.51 & 5.06 & 5.51 & 6.08 \\
\hline \multicolumn{6}{|c|}{ Bulk resistivity $\rho_{B R}[\mathrm{k} \Omega \mathrm{cm}]$} \\
\hline SLWAC & 3.12 & 3.57 & 3.65 & 3.70 & 4.49 \\
\hline SLWAC $+0.5 \%$ & 2.67 & 2.89 & 3.22 & 3.52 & 3.90 \\
\hline SLWAC+1.0\% & 2.07 & 2.43 & 2.82 & 3.05 & 3.56 \\
\hline SLWAC $+1.5 \%$ & 1.69 & 1.93 & 2.17 & 2.36 & 2.60 \\
\hline \multicolumn{6}{|c|}{ Diffusion coefficient $\mathrm{D}_{\mathrm{c}}\left[\mathrm{ms}^{-2}\right]$} \\
\hline SLWAC & $2.37 \times 10^{-11}$ & $2.07 \times 10^{-11}$ & $2.03 \times 10^{-11}$ & $2.00 \times 10^{-11}$ & $1.65 \times 10^{-11}$ \\
\hline SLWAC $+0.5 \%$ & $2.77 \times 10^{-11}$ & $2.56 \times 10^{-11}$ & $2.30 \times 10^{-11}$ & $2.11 \times 10^{-11}$ & $1.90 \times 10^{-11}$ \\
\hline SLWAC $+1.0 \%$ & $3.57 \times 10^{-11}$ & $3.05 \times 10^{-11}$ & $2.63 \times 10^{-11}$ & $2.43 \times 10^{-11}$ & $2.09 \times 10^{-11}$ \\
\hline SLWAC $+1.5 \%$ & $4.37 \times 10^{-11}$ & $3.84 \times 10^{-11}$ & $3.42 \times 10^{-11}$ & $3.14 \times 10^{-11}$ & $2.84 \times 10^{-11}$ \\
\hline
\end{tabular}

Values measured in the reference project [7] have been taken over for a comparison of the results. The results are presented in the paper in the form of conductivity 
of the mixtures in time - Fig. 4, the results of conductivity of mixtures tested in this article are shown in Fig. 5. It should be noted that a higher value of the electrical conductivity of the concrete is related to a higher diffusivity. However, it is necessary to take into account the electrical properties of the fibre in the mixture.

From the reference project [7] results that, in general, the conductivity increases with added fibre and decreases in time, but in the case of SCC $2 \%$ even slightly increases in time. In the case of SLWAC, the conductivity declines for every type of mixture.

By comparing the two graphs, it is obvious that SLWAC shows different behaviour related to conductivity than concrete from the reference project. It was expected that the amount of fibre increases the conductivity and this assumption has been confirmed. But in the matter of values, the new concrete shows much higher conductivity during the whole time, which means that the diffusion properties are worse. This phenomenon needs to be proven also by different testing methods (e.g. Nordtest NTBuild 443 [21]).

In the reference mixture SCC $2 \%$ the corrosion started right after the casting, which significantly influenced the results (conductivity increased). For the four new mixtures, this phenomenon has not yet shown to the fullest. Therefore, the new concrete mixtures show similar progress over the time and it is possible to determine the effect of the amount of fibre to the electrical characteristics.

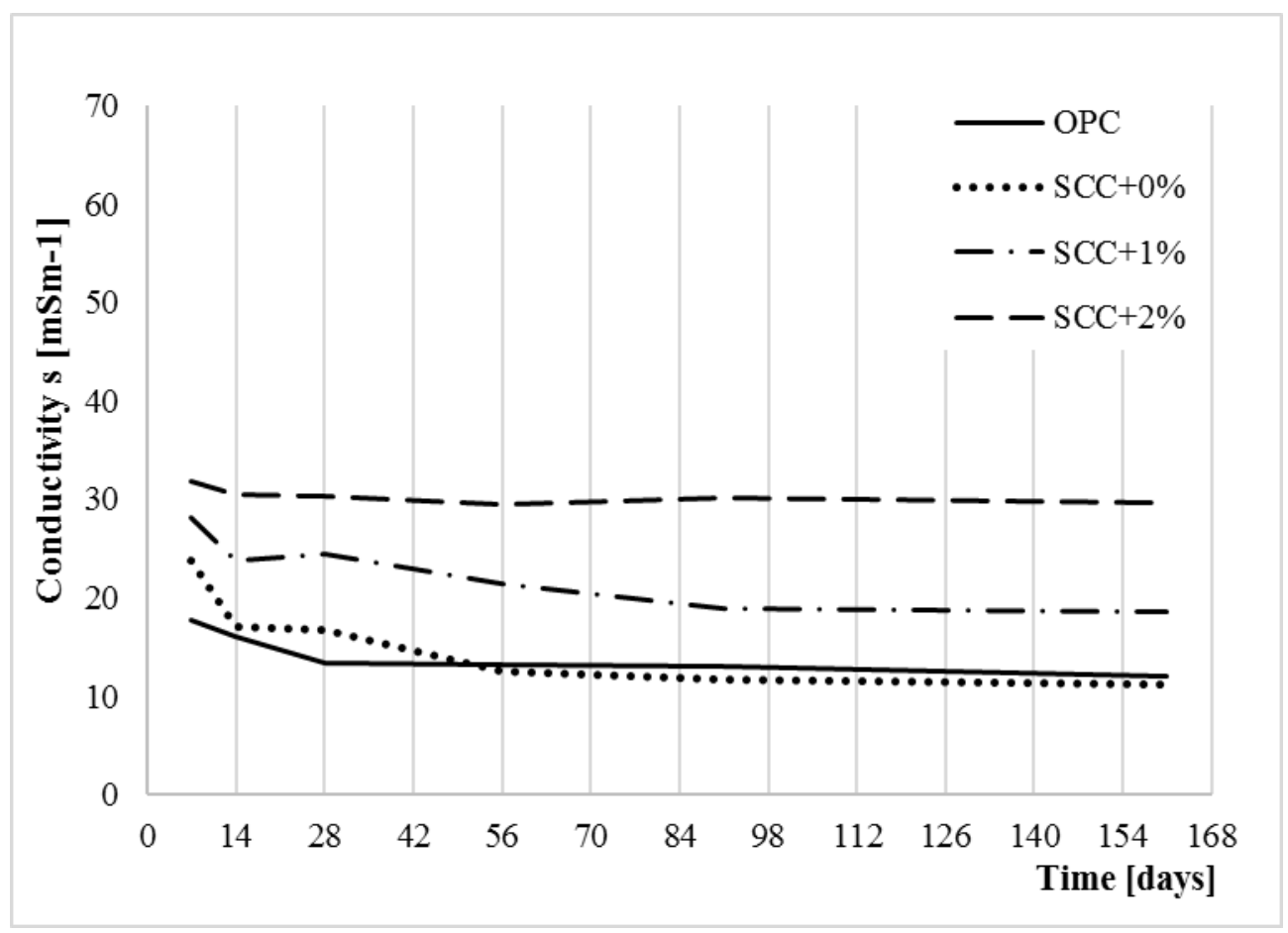

Fig. 4. Results of conductivity in time for all mixtures tested in the reference project [7]. 


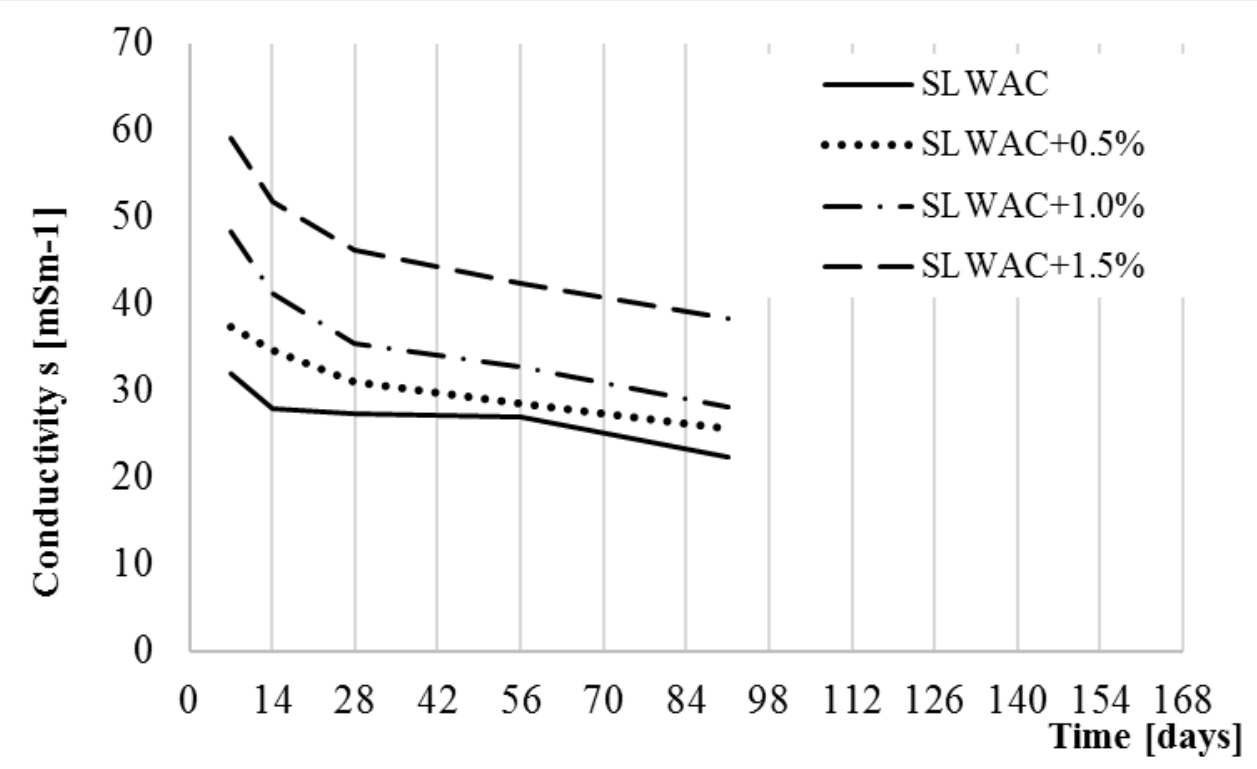

Fig. 5. Results of conductivity in time for all tested mixtures.

\section{Conclusions}

The aim of the article was to observe the durability of the newly designed structural lightweight concrete mixture, which has been prepared to study the material characteristic of concrete made of pre-soaked waste red ceramic fine aggregate and pre-soaked artificial expanded clay coarse aggregate reinforced by copper-coated steel fibre.

Based on the result, there can be seen a nonlinear correlation between the conductivity and amount of fibre. In general, the resistivity increases (conductivity decreases) in time, which means that the concrete becomes more resistant over the time. This phenomenon can be caused by the process of gradual hydration of the cement influenced by the pre-soaked aggregate. However, the used aggregate has a very porous structure, so in comparison with OPC and SCC mixture, the concrete durability is very poor.

The presented results are a section of a research programme that includes testing of the material characteristics and other durability tests. However, the programme is still in progress and the results will be published in the following articles.

The financial supports of the Ministry of Education, Youth and Sports of the Czech Republic through VSB - TU Ostrava (SGS SP2019/126) and grant programme „Support for Science and Research in the Moravia-Silesia Region 2018" (RRC/10/2018), financed from the budget of the MoravianSilesian Region, are highly acknowledged.

\section{References}

1. B. Topçu, N.F. Günçan, Cem. Concr. Res. (1995).

2. J. Katzer, E. Kuźmińska, Sustain. Constr. Mater. Technol., (2016).

3. A. Rao, K.N. Jha, S. Misra, Resour. Conserv. Recycl. 50, 71-81 (2007).

4. O. Zimbili, W. Salim, M. Ndambuki, Int. J. Civ. Environ. Eng. (2014). 
5. M. Horňáková, J. Katzer, J. Kobaka, P. Konečný. Lightweight SFRC Benefitting from Pre-soaking and Internal Curing Process, (2019) - in preparation.

6. J. Liu, C. Shi, X. Ma, K.H. Khayat, J. Zhang, D. Wang, Constr. Build. Mater. 146, 702-712 (2017).

7. P. Konečný, P. Lehner, T. Ponikiewski. Res. and Mod. in Civil Eng. 355, 7-18 (Koszalin, 2018).

8. T. Dyer, Corrosion of Steel Reinforcement in Concrete, in: Concr. Durab., (2014).

9. M.D.A. Thomas, R.D. Hooton, A. Scott, H. Zibara, Cem. Concr. Res. (2012).

10. M. Saillio, V. Baroghel-Bouny, F. Barberon, Constr. Build. Mater. 68, 82-91 (2014).

11. Z. Šmerda, J. Adámek, Z. Keršner, V. Meloun, V. Mencl, D. Novák, P. Rovnaníková, B. Teplý, Durability of the concrete structures, Inf. centre ČKAIT, Prague, (1999).

12. E. Poulsen, L. Mejlbro. Diffusion of Chloride in Concrete: Theory and Application. Modern concrete technology, (2010).

13. M. Collepardi, A. Marcialis, R. Turrizuani. Journal of Am. Cer. Res. Soc.. 55(10), 534535m (1972).

14. X. Lu, Cem. Concr. Res. (1997).

15. P. Ghosh. Computation of Diffusion Coefficients and Prediction of Corrosion Initiation of Concrete Structures, doctoral thesis, (2011).

16. P. Lehner, M. Turicová, P. Konečný. ARPN Jour. of Eng. and App. Scien. 12. 937-944 (2017).

17. H. Layssi, P. Ghods, A. Alizadeh, M. Salehi. Con. Inter. 37, 41-46 (2015).

18. W. Morris, E.I. Moreno, A.A. Sagüés, Cem. Concr. Res. (1996).

19. AASHTO-TP95, AASHTO Provisional Standards, 95-11 (2011).

20. ASTM C1202, American Society for Testing and Materials, (2012).

21. NT Build 443, (1995). 